\title{
Estudo comparativo da ação da toxina botulínica tipo A e da crotoxina sobre as células satélites da musculatura extrínseca ocular em modelo animal
}

\section{A comparative study of the effects of type A botulinum toxin and crotoxin on satellite cells of extraocular muscles in rabbits}

Marta Halfeld Ferrari Alves Lacordia', Geraldo de Barros Ribeiro², Henderson Celestino de Almeida ${ }^{3}$, Carlos Henrique Reis de Araújo Silva ${ }^{4}$, Maria do Carmo Jordão Coelho ${ }^{5}$, Raul Fernando Binato Lamim ${ }^{6}$

\section{ResUMO}

Objetivos: Avaliar o efeito da toxina botulínica do tipo A e da crotoxina na ativação de células satélites das fibras musculares de retos superiores de coelhos. Métodos: Os músculos retos superiores do olho direito de 29 coelhos machos albinos neozelandeses foram inoculados com toxina botulínica do tipo A ou com crotoxina, em diferentes doses. Os músculos retos superiores contralaterais de cada animal foram inoculados com solução salina em volume igual ao das toxinas. Os animais foram sacrificados 12,18 ou 25 dias após as aplicações. Os olhos foram enucleados e cada músculo foi preparado para análise imunoistoquímica, com marcadores de células satélites. Foi realizada contagem dos núcleos corados pelos marcadores a cada cem miofibras. Resultados: A aplicação de toxina botulínica e de crotoxina provocou um aumento no número de células satélites ativadas e em proliferação nos músculos retos superiores. Uma maior ativação foi observada após a aplicação de crotoxina, embora, estatisticamente, a diferença do efeito de ativação entre os grupos botoxina e crotoxina não tenha sido significativa. Nos grupos botoxina e crotoxina, não houve correlação estatisticamente significativa entre a dose e o volume aplicados e o aumento na ativação das células. O tempo de vida após a aplicação contribuiu para o aumento das células ativadas nos grupos. Conclusão: A observação de maior desorganização na estrutura muscular e de sinais de regeneração mais evidentes no grupo crotoxina parece estar correlacionada ao aumento de células satélites ativadas.

Descritores: Células satélites de músculo esquelético /efeito de drogas; Toxina botulínica tipo A; Crotoxina; Estrabismo; Fibras musculares/efeito de drogas.

'Doutora em Oftalmologia pela Universidade Federal de Minas Gerais - UFMG - Belo Horizonte (MG), Oftalmologista e Chefe do Serviço de Oftalmologia do Hospital Universitário da Universidade Federal de Juiz de Fora - UFJF - Juiz de Fora (MG), Brasil. ${ }^{2}$ Doutor em Medicina, Professor Voluntário do Serviço de Estrabismo do Hospital São Geraldo, da Universidade Federal de Minas Gerais - UFMG - Belo Horizonte (MG), Brasil.

${ }^{3}$ Professor Titular e chefe do Serviço de Estrabismo do Hospital São Geraldo, da Universidade Federal de Minas Gerais - UFMG - Belo Horizonte (MG), Brasil.

${ }^{4}$ Médico veterinário, Diretor da Faculdade de Ciências da Saúde da Universidade Presidente Antônio Carlos - UNIPAC, Campus VI, Juiz de Fora (MG), Brasil.

${ }_{5}^{5}$ Professora Adjunta do Departamento de Patologia da Faculdade de Medicina da Universidade Federal de Juiz de Fora - UFJF - Juiz de Fora (MG), Brasil.

${ }^{6}$ Professor Adjunto do Departamento de Patologia da Faculdade de Medicina da Universidade Federal de Juiz de Fora - UFJF - Juiz de Fora (MG), Brasil.

Trabalho realizado na Universidade Federal de Minas Gerais, na Universidade Federal de Juiz de Fora, na Faculdade de Medicina Veterinária da Universidade Presidente Antônio Carlos (UNIPAC, Campus VI - Juiz de Fora, MG) e no Departamento de Anatomopatologia da Santa Casa de Misericórdia de Juiz de Fora, MG, sendo apresentado como requisito parcial à obtenção do grau acadêmico de Doutor em Medicina pela Universidade Federal de Minas Gerais.

Recebido para publicação em: 18/5/2009 - Aceito para publicação em 12/7/2009 


\section{INTRODUÇÃO}

O músculo esquelético é um tecido capaz de responder a estímulos fisiológicos (como exercícios intensos) ou a traumas severos através de respostas regenerativas bem organizadas que restauram sua arquitetura em um período de duas semanas ${ }^{(1)}$. Essa capacidade de regeneração é atribuída a uma população de células que foram, em 1961, identificadas e descritas pela primeira vez por Alexander Mauro, em fibra muscular esquelética de rãs. Ele denominou-as células satélites (CS) devido à sua localização na periferia da fibra muscular ${ }^{(2)}$. Enquanto o tecido muscular esquelético encontra-se livre de agressões, as CS permanecem em um estado não proliferativo, ou seja, em estado quiescente. Em resposta a estímulos (como um trauma) as CS tornam-se ativas, proliferam-se, expressam marcadores miogênicos, fundem-se a fibras musculares pré-existentes ou a CS vizinhas para formar novas fibras musculares ${ }^{(1)}$.

Ao contrário da musculatura esquelética, que é pós-mitótica, os músculos oculares extrínsecos (MOE) apresentam-se em contínua renovação celular devido às CS. McLoon e Wirtschafter descreveram cerca de $2 \%$ a $4 \%$ de CS positivas para Myo D (myogenic determination gene $D$ ) em fibras da musculatura ocular externa de coelhos, macacos e humanos adultos e sem sinais de trauma. Observaram também, em ratos e coelhos, a adição de novos mionúcleos às fibras pré-existentes. Isso sugere que os MOE estão em contínua renovação, o que não ocorre, por exemplo, em músculo esquelético adulto dos membros ${ }^{(3-6)}$.

O estrabismo é um desalinhamento dos olhos, freqüentemente associado à hiper ou hipofunção de MOE. O objetivo do tratamento cirúrgico do estrabismo é equilibrar as forças geradas pelos $\mathrm{MOE}$, de maneira que, na presença de impulsos motores eferentes anormais, o alinhamento binocular normal possa ser alcançado ou mantido. A cirurgia compromete a dinâmica muscular normal e, inevitavelmente, provoca cicatrizes, incomitâncias e, ocasionalmente, estrabismos secundários ${ }^{(7,8)}$.

A toxina botulínica do tipo A, aprovada para uso clínico há mais de uma década, tem sido utilizada eficazmente para o enfraquecimento de músculos hiperfuncionantes no estrabismo de adultos e crianças. Porém, a necessidade de se descobrir um tratamento farmacológico para o estrabismo, que não cause enfraquecimento muscular permanente, mas que tenha uma duração maior que a da toxina botulínica, estimula a comunidade científica a pesquisar novas substâncias. Estudos recentes verificaram que a crotoxina foi capaz de induzir uma paralisia transitória em músculo reto superior de coelhos; além disso, sua ação e seu efeito foram semelhantes aos da toxina botulínica do tipo A.O conhecimento da participação das células satélites no funcionamento dos MOE, assim como os métodos de se controlar a ativação dessas células, têm se tornado um campo de estudo de grande interesse ${ }^{(9-11)}$.

O objetivo deste estudo foi avaliar o efeito da toxina botulínica do tipo A e da crotoxina na ativação de CS das fibras musculares de músculos retos superiores de coelhos.

\section{MéTodos}

Este estudo experimental e longitudinal foi realizado no biotério da Faculdade de Medicina Veterinária da Universidade Presidente Antônio Carlos (UNIPAC) - Juiz de Fora, Minas Gerais, e foi aprovado pelo Comitê de Ética em Experimentação Animal (CETEA/UFMG). Foram utilizados 29 coelhos machos albinos, da raça Nova Zelândia, com peso variando de $1,5 \mathrm{~kg}$ a $2,5 \mathrm{~kg}$, clinicamente sadios, provenientes da Fazenda Veterinária da Universidade Federal de Minas Gerais (Igarapé - MG).A pesquisa foi conduzida obedecendo-se aos critérios recomendados pelo Colégio Brasileiro de Experimentação Animal (COBEA) e respeitando a Lei Federal Brasileira número 6 638, de maio de 1979. Os animais foram mantidos em gaiolas suspensas, com água e ração específica para a espécie ad libitum e divididos aleatoriamente em dois grupos: botoxina (GB) e crotoxina (GCrtx).

Após a instilação de colírio anestésico de cloridrato de benoxinato a $0,4 \%$ (oxibuprocaína) no saco conjuntival de cada olho direito, colocou-se um blefarostato. Usando-se uma pinça denteada para elevar a conjuntiva, uma agulha acoplada à seringa de insulina (BD Plastipak - Becton Dickinson Ind. Cirúr. Ltda., Curitiba - PR), contendo ou Botox ${ }^{\circledR}$ (Allergan Pharmaceuticals Ltd - Westport, Irlanda) ou crotoxina (cedida pela Divisão de Imunológicos da Fundação Ezequiel Dias de Belo Horizonte - Minas Gerais [FUNED]), foi introduzida transconjuntivalmente e penetrada no músculo reto superior, a aproximadamente 4 $\mathrm{mm}$ da inserção muscular. A toxina foi injetada lentamente. O mesmo processo foi executado no olho esquerdo com a aplicação de solução salina em igual volume. 
O QUADRO 1 mostra as doses de toxina botulínica e de crotoxina aplicadas em cada coelho. O coelho 5 apresentava atrofia ocular esquerda, por trauma perfurante, não tendo sido, portanto, aplicada a solução no músculo reto superior de tal olho.

Após a aplicação das toxinas e da solução fisiológica, os coelhos foram examinados diariamente para observação de existência de efeitos adversos locais e sistêmicos. Não houve mudança comportamental. Observou-se ptose palpebral moderada no olho direito dos coelhos 1, 2,3, 4, 5, 6, 7, 8, 9, 10, 15, 16, 17, 18, 19, 20, 21, 22, 23 e 24 e ptose discreta nos coelhos 11, 12, 13, 14, 25, 26, 27, 28 e 29, com duração média de cinco dias. No olho esquerdo de todos os coelhos, não houve ptose palpebral. Houve sinais de hiperemia conjuntival em todos os coelhos no primeiro dia após a aplicação, mas tais sinais desapareceram, na maioria dos animais, no terceiro após a aplicação. Não foi observada secreção conjuntival.

Os animais foram sacrificados por médico veterinário, nos momentos estabelecidos (12,18 ou 25 dias após as aplicações), com tiopental sódico (Thiopentax ${ }^{\circledR}$ - Cristália), na dosagem de $20 \mathrm{mg} / \mathrm{kg}$, seguido de injeção intracardíaca de cloreto de potássio a $10 \%$. Os coelhos $1,6,11,15,20$ e 25 foram sacrificados no $12^{\circ}$ dia após as aplicações; os coelhos 2, 3, 7, 8, 12, 16, 17, 21, 22, 26 e 27, no $18^{\circ}$ dia; os coelhos 4, 5, 9, 10,13, 14, 18, 19, 23, 24, 28 e 29 no $25^{\circ}$ dia.

Posteriormente, os olhos foram cuidadosamente enucleados, mantendo-se os músculos retos superiores intactos. Os globos oculares foram colocados em frascos numerados, com formol tamponado a $10 \%$. Os músculos retos superiores foram desinseridos dos globos oculares. Cada músculo foi colocado em cassete plástico, identificado com o mesmo número contido no frasco de origem e levado para processamento histológico. Lâminas foram montadas, preparadas e coradas com hematoxilina eosina e marcadores de células satélites Myo D e PCNA (proliferating cell nuclear antigen).

As lâminas tiveram suas identificações recobertas durante a análise anátomo-patológica e também durante a contagem das CS, realizada por patologista experiente. Foram examinadas em microscópio da marca Nikon cem miofibras escolhidas ao acaso, com aumento de mil vezes (ocular de dez vezes e objetiva de cem vezes); foi feita a contagem dos núcleos positivos para o Myo D e para o PCNA, bem como a contagem do total de CS (núcleos positivos e negativos para os marcadores).

Os dados foram analisados, calculando-se as médias aritméticas, o desvio padrão e a amplitude da variação. As variáveis independentes foram representadas pelas substâncias injetadas no músculo reto superior do olho direito dos coelhos, bem como pelos co-fatores tempo de vida após a aplicação, volume aplicado e dose das substâncias. As variáveis dependentes foram representadas pela porcentagem de núcleos de CS ativados.

A avaliação do efeito foi realizada pela medida da ativação dos núcleos de células satélites, pelos dois marcadores, segundo o cálculo:

$\%$ núcleos ativados $=\mathrm{n}^{\circ}$ de núcleos ativados $/ 100$ miofibras/total de núcleos/100 miofibras

O modelo estatístico empregou a comparação de médias de porcentagem de núcleos de CS ativados entre os grupos definidos pelo tipo de substância. Para avaliar a diferença das médias de porcentagem de núcleos de CS ativados entre os grupos de substâncias, utilizouse o teste de ANOVA, quando foram atendidos os pressupostos de normalidade e homogeneidade das variâncias. No caso do não atendimento dos pressupostos, foi utilizado o teste não paramétrico de Kruskal-Wallis. Para avaliação da normalidade, foi utilizado o teste de KolmogorovSmirnov. Para avaliação da homogeneidade das variâncias, utilizou-se o teste de Levene. Para avaliar a existência de correlação entre o percentual de núcleos ativados, as doses, os volumes e os dias de vida após a aplicação, foram utilizados o coeficiente de Pearson e a inspeção do diagrama de dispersão. A interferência dos co-fatores nas associações foi avaliada com o teste ANOVA de dois critérios, quando atendidos os pressupostos dos testes paramétricos. Todos os resultados foram considerados significativos, em um nível de significância de $5 \%(\alpha=0,05)$. Valores de $\mathrm{p}$ entre 0,05 e 0,10 foram considerados marginalmente significativos.

\section{Resultados}

Dos 57 músculos retos superiores de coelhos estudados, 14 receberam aplicação de toxina botulínica (grupo botoxina), 15 receberam crotoxina (grupo crotoxina) e 28 receberam solução salina (grupo controle). A tabela 1 esquematiza os percentuais de núcleos marcados pelo Myo D e pelo PCNA nos grupos estudados. Após a realização dos testes para a análise entre os grupos dos percentuais de contagem dos núcleos marcados respectivamente pelo Myo D e pelo PCNA, notou-se que a diferença entre os efeitos mensurados foi estatisticamente significativa $(p=0,000)$. Não houve diferença estatis- 
Quadro 1

Toxina botulínica e crotoxina aplicadas no m.RS do OD dos coelhos 1 a 29

\begin{tabular}{|c|c|c|c|c|}
\hline $\begin{array}{r}\text { Identificação } \\
\text { dos coelhos }\end{array}$ & $\begin{array}{c}\text { Toxina aplicada } \\
\text { e dosagem }\end{array}$ & Volume aplicado & Data da aplicação & $\begin{array}{l}\text { Músculo em } \\
\text { que foi aplicada }\end{array}$ \\
\hline 1 & Botox $^{\circledR} 10 \mathrm{U}$ & $0,5 \mathrm{ml}$ & $25 / 11 / 2006$ & RS OD* \\
\hline 2 & Botox $^{\circledR} 10 \mathrm{U}$ & $0,5 \mathrm{ml}$ & 25/11/2006 & RS OD \\
\hline 3 & Botox $^{\circledR} 10 \mathrm{U}$ & $0,5 \mathrm{ml}$ & $25 / 11 / 2006$ & RS OD \\
\hline 4 & Botox $^{\circledR} 10 \mathrm{U}$ & $0,5 \mathrm{ml}$ & $25 / 11 / 2006$ & RS OD \\
\hline 5 & Botox $^{\circledR} 10 \mathrm{U}$ & $0,5 \mathrm{ml}$ & $25 / 11 / 2006$ & RS OD \\
\hline 6 & Botox $^{\circledR} 5 \mathrm{U}$ & $0,25 \mathrm{ml}$ & $25 / 11 / 2006$ & RS OD \\
\hline 7 & Botox $^{\circledR} 5 \mathrm{U}$ & $0,25 \mathrm{ml}$ & $25 / 11 / 2006$ & RS OD \\
\hline 8 & Botox $^{\circledR} 5 \mathrm{U}$ & $0,25 \mathrm{ml}$ & $25 / 11 / 2006$ & RS OD \\
\hline 9 & Botox $^{\circledR} 5 \mathrm{U}$ & $0,25 \mathrm{ml}$ & $25 / 11 / 2006$ & RS OD \\
\hline 10 & Botox $^{\circledR} 5 \mathrm{U}$ & $0,25 \mathrm{ml}$ & $25 / 11 / 2006$ & RS OD \\
\hline 11 & Botox $^{\circledR} 2,5 \mathrm{U}$ & $0,1 \mathrm{ml}$ & $25 / 11 / 2006$ & RS OD \\
\hline 12 & Botox $^{\circledR} 2,5 \mathrm{U}$ & $0,1 \mathrm{ml}$ & $25 / 11 / 2006$ & RS OD \\
\hline 13 & Botox $^{\circledR} 2,5 \mathrm{U}$ & $0,1 \mathrm{ml}$ & $25 / 11 / 2006$ & RS OD \\
\hline 14 & Botox $^{\circledR} 2,5 \mathrm{U}$ & $0,1 \mathrm{ml}$ & $25 / 11 / 2006$ & RS OD \\
\hline 15 & Crotoxina10 U & $0,5 \mathrm{ml}$ & $25 / 11 / 2006$ & RS OD* \\
\hline 16 & Crotoxina10 U & $0,5 \mathrm{ml}$ & $25 / 11 / 2006$ & RS OD \\
\hline 17 & Crotoxina10 U & $0,5 \mathrm{ml}$ & $25 / 11 / 2006$ & RS OD \\
\hline 18 & Crotoxina10 U & $0,5 \mathrm{ml}$ & $25 / 11 / 2006$ & RS OD \\
\hline 19 & Crotoxina10 U & $0,5 \mathrm{ml}$ & $25 / 11 / 2006$ & RS OD \\
\hline 20 & Crotoxina $5 \mathrm{U}$ & $0,25 \mathrm{ml}$ & $25 / 11 / 2006$ & RS OD \\
\hline 21 & Crotoxina $5 \mathrm{U}$ & $0,25 \mathrm{ml}$ & $25 / 11 / 2006$ & RS OD \\
\hline 22 & Crotoxina $5 \mathrm{U}$ & $0,25 \mathrm{ml}$ & $25 / 11 / 2006$ & RS OD \\
\hline 23 & Crotoxina $5 \mathrm{U}$ & $0,25 \mathrm{ml}$ & $25 / 11 / 2006$ & RS OD \\
\hline 24 & Crotoxina $5 \mathrm{U}$ & $0,25 \mathrm{ml}$ & $25 / 11 / 2006$ & RS OD \\
\hline 25 & Crotoxina $2 \mathrm{U}$ & $0,1 \mathrm{ml}$ & $25 / 11 / 2006$ & RS OD \\
\hline 26 & Crotoxina $2 \mathrm{U}$ & $0,1 \mathrm{ml}$ & $25 / 11 / 2006$ & RS OD \\
\hline 27 & Crotoxina $2 \mathrm{U}$ & $0,1 \mathrm{ml}$ & $25 / 11 / 2006$ & RS OD \\
\hline 28 & Crotoxina $2 \mathrm{U}$ & $0,1 \mathrm{ml}$ & $25 / 11 / 2006$ & RS OD \\
\hline 29 & Crotoxina $2 \mathrm{U}$ & $0,1 \mathrm{ml}$ & $25 / 11 / 2006$ & RS OD \\
\hline
\end{tabular}

*Reto superior do olho direito

Tabela 1

Percentuais de núcleos marcados pelo Myo D e pelo PCNA nos grupos controle, botoxina e crotoxina:

\begin{tabular}{lcccccc}
\hline Marcadores & Grupos & $\mathbf{N}$ & Média & $\begin{array}{c}\text { Desvio } \\
\text { padrão }\end{array}$ & $\begin{array}{c}\text { Valor } \\
\text { mínimo }\end{array}$ & $\begin{array}{c}\text { Valor } \\
\text { máximo }\end{array}$ \\
\hline MyoD $(\mathrm{p}=0,000)$ & Controle & 28 & 33,6 & 11,20 & 14,4 & 51,8 \\
& Botoxina & 14 & 47,6 & 13,12 & 30,1 & 66,9 \\
& Crotoxina & 15 & 52,2 & 14,01 & 23,4 & 71,0 \\
PCNA $(\mathrm{p}=0,000)$ & & & & & & \\
& Controle & 28 & 37,3 & 10,70 & 12,2 & 54,3 \\
& Botoxina & 14 & 51,7 & 16,80 & 23,7 & 72,0 \\
& Crotoxina & 15 & 56,9 & 11,47 & 35,7 & 73,4 \\
\hline
\end{tabular}


ticamente significativa entre os grupos botox e crotoxina em relação aos núcleos corados pelo Myo $\mathrm{D}(\mathrm{p}=0,374)$ e pelo PCNA $(\mathrm{p}=0,485)$. A tabela 2 demonstra que as relações entre a dose aplicada e a resposta e o volume aplicado e a resposta não foram significativas em nenhum dos grupos analisados. A tabela 3 demonstra que a relação entre os dias de vida após a aplicação foi estatisticamente significativa em todos os grupos analisados.

As lâminas com cortes histológicos dos músculos retos superiores dos grupos deste estudo foram também analisadas com coloração de hematoxilina-eosina. Nos grupos controle, botoxina e crotoxina, as alterações musculares observadas no músculo reto superior foram focais, ou seja, encontradas no local da aplicação das substâncias.

\section{Discussão}

Christiansen et al. (2000) injetaram ricin-mAb 35 no músculo reto superior de coelhos, com o objetivo de determinar os efeitos histológicos e ultra-estruturais nos músculos. Verificaram lesões focais dose-dependentes, processos inflamatórios auto-limitantes e significante perda de fibras musculares. Notaram uma lenta regeneração das miofibras ${ }^{(7)}$. Em 2003, Christiansen et al. voltaram a estudar os efeitos dessa imunotoxina na força muscular de músculo extrínseco ocular. Concluíram que esse lento processo de regeneração poderia explicar a longa duração da ação da ricin-mAb 35. Demonstraram através de estudos histológicos que a aplicação da substância resultava em lesão citotóxica discreta, com boa preservação das miofibras periféricas no local da injeção. Sugeriram que a ricin-mAb poderia ser uma alternativa para o retrocesso cirúrgico e também uma opção mais duradoura que a toxina botulínica no tratamento farmacológico do estrabismo ${ }^{(12)}$.

Ugalde et al. (2005) observaram que a paralisia dos MOE induzida por toxina botulínica em olhos de coelhos resultou em aumento da ativação de CS a curto intervalo de tempo, em comparação com olhos em que havia sido injetada solução salina ${ }^{(13)}$.

Tabela 2

Percentuais de núcleos corados pelo Myo D e pelo PCNA nos grupos, de acordo com os volumes e doses:

\begin{tabular}{|c|c|c|c|c|c|c|}
\hline Grupos & $\begin{array}{l}\text { Volume } \\
\text { Dose }\end{array}$ & $\mathbf{N}$ & Média & $\begin{array}{l}\text { Desvio } \\
\text { padrão }\end{array}$ & $\begin{array}{l}\text { Valor } \\
\text { mínimo }\end{array}$ & $\begin{array}{c}\text { Valor } \\
\text { máximo }\end{array}$ \\
\hline Botoxina & $0,10 \mathrm{ml}(2,5 \mathrm{U})$ & 4 & 46,84 & 12,25 & 35,65 & $58 f) 7$ \\
\hline Marcador & $0,25 \mathrm{ml}(5 \mathrm{U})$ & 5 & 45,60 & 15,45 & 31,10 & 66,87 \\
\hline $\begin{array}{l}\text { M)QD } \\
(p=0,864)^{*}\end{array}$ & $0,50 \mathrm{ml}(10 \mathrm{U})$ & 5 & 50,30 & 13,91 & $30,<X>$ & 64,65 \\
\hline Botoxina & $0,10 \mathrm{ml}(2,5 \mathrm{U})$ & 4 & 54,12 & 17,58 & 34,38 & 70,54 \\
\hline Marcador & $0,25 \mathrm{ml}(5 \mathrm{U})$ & 5 & 46,95 & 19,28 & 23,66 & 72,05 \\
\hline $\begin{array}{l}\text { PCNA } \\
(p=0,761)^{* *}\end{array}$ & $0,50 \mathrm{ml}(10 \mathrm{U})$ & 5 & 54,51 & 16,42 & 27,73 & 68,01 \\
\hline Crotoxina & 0,10ml(2 U) & 5 & 52,31 & 14,11 & 28,91 & 64,95 \\
\hline Marcador & $0,25 \mathrm{ml}(5 \mathrm{U})$ & 5 & 50,43 & 18,26 & 23,37 & 71,02 \\
\hline $\begin{array}{l}\text { M)QD } \\
(\mathrm{p}=0,936)^{*}\end{array}$ & $0,50 \mathrm{ml}\left(1^{\circ} \mathrm{U}\right)$ & 5 & 53,88 & 12,12 & 37,56 & 69,13 \\
\hline Crotoxina & $0,10 \mathrm{ml}(2 \mathrm{U})$ & 5 & 58,53 & 14,94 & 35,75 & 73,38 \\
\hline Marcador & $0,25 \mathrm{ml}(5 \mathrm{U})$ & 5 & 55,59 & 8,40 & 42,86 & 64,44 \\
\hline $\begin{array}{l}\text { PCNA } \\
(\mathrm{p}=0,852)^{* *}\end{array}$ & $0,50 \mathrm{ml}\left(1^{\circ} \mathrm{U}\right)$ & 5 & 56,61 & 12,68 & 38,05 & 70,61 \\
\hline Controle & $0,10 \mathrm{ml}$ & 9 & 38,58 & 10,59 & 17,23 & 48,28 \\
\hline Marcador & $0,25 \mathrm{ml}$ & 10 & 31,81 & 12,28 & 14,39 & 51,78 \\
\hline $\begin{array}{l}\text { M)QD } \\
(\mathrm{p}=0,269)^{*}\end{array}$ & $0,50 \mathrm{ml}$ & 9 & 30,56 & 9,99 & 19,05 & 45,19 \\
\hline Controle & $0,10 \mathrm{ml}$ & 9 & 26,09 & 11,11 & 12,18 & 42,48 \\
\hline Marcador & $0,25 \mathrm{ml}$ & 10 & 35,26 & 7,75 & 24,13 & 48,30 \\
\hline $\begin{array}{l}\text { PCNA } \\
(\mathrm{p}=0,676) * *\end{array}$ & $0,50 \mathrm{ml}$ & 9 & 45,44 & 5,86 & 32,17 & 54,27 \\
\hline
\end{tabular}

ANOVA; ** Teste de Kruskal-Wallis 
Este estudo confirma tais relatos, demonstrando haver um aumento significativo na ativação das CS após a utilização da toxina botulínica e, de forma um pouco mais acentuada, após a aplicação da crotoxina. O estudo histológico das fibras musculares dos grupos botoxina e crotoxina revelou sinais de regeneração, sem apresentar sinais significantes de atrofia muscular. Demonstrou também que as lesões foram focais. Ao contrário do que foi demonstrado por Christiansen et al., verificou-se que a dosagem das toxinas não foi tão importante no acréscimo das CS. O volume de solução salina ou de toxina aplicado também não influenciou no aumento das CS. Os animais sacrificados mais tardiamente apresentaram maior aumento na ativação das CS e pouco desarranjo da arquitetura das fibras musculares.

Porter et al. demonstraram que as alterações histológicas causadas pela toxina botulínica são reversíveis ${ }^{(14)}$. Supõe-se que o aumento na ativação das CS es- teja diretamente relacionado à regeneração das fibras.

Neste estudo, observou-se, no exame histológico do grupo crotoxina, maior agressão na estrutura das fibras e sinais de regeneração mais evidentes, o que poderia estar correlacionado com o aumento de CS ativadas. Quando foram aplicadas $10 \mathrm{U}$ de toxinas, o grupo crotoxina ainda apresentou alterações histológicas marcantes após 26 dias (núcleos reativos e fibras em necrose); já no grupo botoxina a arquitetura das fibras musculares foi reestruturada. Acredita-se que o processo de regeneração das fibras musculares após a aplicação da crotoxina seja mais lento que após a aplicação da toxina botulínica, o que poderia explicar a ação mais duradoura da crotoxina. Entretanto, Ribeiro (2001) verificou que a crotoxina e a toxina botulínica produziram paralisia transitória do músculo reto superior de coelhos, de maneira semelhante, em determinadas concentrações ${ }^{(11)}$.

Considerando-se os estágios regenerativos do pro-

Tabela 3

Percentuais de núcleos corados pelo Myo D e pelo PCNA nos grupos, de acordo com os dias de vida após a aplicação:

\begin{tabular}{|c|c|c|c|c|c|c|}
\hline & Dias de vida & $\mathbf{N}$ & Média & $\begin{array}{c}\text { Desvio } \\
\text { p,adrão }\end{array}$ & $\begin{array}{l}\text { Valor } \\
\text { mínimo }\end{array}$ & $\begin{array}{l}\text { Valor } \\
\text { máximo }\end{array}$ \\
\hline Botoxina & 13 & 3 & 32,70 & 3,71 & 30,06 & 36,95 \\
\hline Matador & 19 & 5 & 45,87 & 13,54 & 33,43 & 64,65 \\
\hline $\begin{array}{l}\text { M)QD } \\
(\mathrm{p}=0,018)^{*}\end{array}$ & 26 & 6 & 56,58 & 7,91 & 42,59 & $f i 5,87$ \\
\hline Botoxina & 13 & 3 & 28,59 & 5,41 & $23, f i 5$ & 34,38 \\
\hline Marcador & 19 & 5 & 50,41 & 13,44 & 36,70 & 68,01 \\
\hline $\begin{array}{l}\text { PCNA } \\
(\mathrm{p}=0,016) * *\end{array}$ & 26 & 6 & 64,33 & 7,98 & 50,33 & 72,05 \\
\hline Crotoxina & 13 & 3 & 29,95 & 7,15 & 23,37 & 37,56 \\
\hline Man:ador & 19 & 6 & 50,31 & 2,84 & 45,45 & 53,85 \\
\hline $\begin{array}{l}\text { M)QD } \\
\left(\mathrm{p}=0,00:{ }^{*} *\right.\end{array}$ & 26 & 6 & 65,23 & 3,96 & 61,62 & 71,02 \\
\hline Crotoxina & 13 & 3 & 38,88 & 3,63 & 35,75 & 42,86 \\
\hline Marcador & 19 & 6 & 55,14 & 2,27 & 52,22 & 58,77 \\
\hline $\begin{array}{l}\text { PCNA } \\
(\mathrm{p}=0,002)^{* *}\end{array}$ & 26 & 6 & 67,70 & 4,40 & 61,78 & 73,38 \\
\hline Controle & 13 & 6 & 22,27 & 10,31 & 14,39 & 42,55 \\
\hline Man:ador & 19 & 11 & 29,83 & 8,33 & 19,71 & 45,49 \\
\hline $\begin{array}{l}\text { M)QD } \\
\left(\mathrm{p}=0,(0 »)^{*}\right.\end{array}$ & 26 & 11 & 43,52 & 3,92 & 38,37 & 51,78 \\
\hline Controle & 13 & 6 & $26, W$ & 11,11 & 12,18 & 42,48 \\
\hline Marcador & 19 & 11 & 35,26 & 7,75 & 24,13 & 48,30 \\
\hline $\begin{array}{l}\text { PCNA } \\
=0.001)^{* *}\end{array}$ & 26 & 11 & 45,44 & 5,86 & 32,17 & 54,27 \\
\hline
\end{tabular}

* ANOVA; ** Teste de Kruskal-Wallis 
cesso de reparação muscular - ativação (iniciada por volta de duas horas após o trauma) e proliferação (iniciada por volta de dois a três dias após o trauma), seguidas da diferenciação e da maturação - foram utilizados os marcadores de CS Myo D (julgado um excelente marcador para CS ativadas) e PCNA (considerado um excelente marcador para CS em proliferação) ${ }^{(1)}$. Notouse um discreto aumento no percentual de núcleos marcados com o PCNA, o que demonstrou a existência de maior porcentagem de CS em proliferação. No entanto, não foi detectada diferença estatisticamente significativa entre o porcentual de núcleos.

Estudos futuros serão necessários para maiores esclarecimentos sobre a ação a longo prazo da toxina botulínica e da crotoxina nas CS da musculatura ocular extrínseca.

\section{Conclusão}

A aplicação de toxina botulínica e de crotoxina provocou aumento no número de células satélites ativadas e em proliferação nos músculos retos superiores de coelhos. Não houve correlação estatisticamente significativa entre a dose aplicada e o aumento na ativação das células satélites nos grupos botoxina e crotoxina; da mesma forma, em todos os grupos, não houve correlação entre o volume de substância aplicada e o aumento na ativação celular. O tempo de vida após a aplicação contribuiu para a elevação do número de células, independentemente da substância utilizada.

Embora tenha ocorrido um maior aumento na ativação de células satélites após a aplicação de crotoxina, estatisticamente, a diferença na ativação celular entre os grupos botoxina e crotoxina não foi significativa. O grupo crotoxina apresentou ao estudo histológico maior desarranjo na arquitetura das fibras musculares e mais evidências de sinais de regeneração, o que pode estar relacionado ao aumento da ativação das células satélites.

Os resultados deste estudo sugerem que o processo de regeneração das fibras musculares após a inoculação da crotoxina seja mais lento que após a inoculação da toxina botulínica, o que pode estar relacionado à ação mais duradoura da crotoxina.

\section{Agradecimentos}

Ao Dr. Márcio José Martins Alves, professor adjunto do Departamento de Saúde Coletiva da Faculdade de Medicina da Universidade Federal de Juiz de Fora, pelo auxílio na análise estatística. Ao Laboratório de Anatomia Patológica da Santa Casa de Misericórdia de Juiz de Fora e, em especial, a Débora Tavares Grizendi, pelo trabalho de preparação das lâminas.

\section{Abstract}

Purpose: To evaluate the effect of botulinum toxin $A$ and crotoxin on satellite cell activation in the muscle fibers of superior rectus muscles of rabbits. Methods: The superior rectus muscles in the right eyes of 29 male, albino, New Zealand rabbits were inoculated with different doses of botulinum toxin A or crotoxin. The contra-lateral superior rectus muscles in each rabbit were inoculated with the same volume of saline solution only. The animals were sacrificed either 12, 18 or 25 days after the inoculation. The eyes were enucleated and subsequently, each muscle was prepared for immunohistochemical analysis, using satellite cell markers. The positive nuclei, revealed by the markers in each 100 myofibers, were counted. Results: The application of the botulinum toxin $A$ and crotoxina triggered a more significant increase satellite cell activation and proliferation in right superior rectus muscles in rabbits when compared with a saline solution inoculation in the contralateral muscles. Greater cell activation was observed after crotoxin application, although, statistically, the difference in the effects of this activation between the botoxin and crotoxin groups was not significant. There was no statistically significant correlation between the dose and the volume applied and resulting cell activation in the botoxin and crotoxin groups. Post-application survival time contributed to the increase in activated satellite cells in all groups. Conclusion: The observed increase in disorganization in the muscle structure, together with more obvious signs of regeneration in the crotoxina group, suggests a correlation with the increase in satellite cell activation.

Keywords: Satellite cells, skeletal muscle/drug effects; Botulinum toxin type A; Crotoxin; Strabismus; Muscle fibers/drug effects.

\section{RefERÊNCIAS}

1. Shi X, Garry DJ. Muscle stem cells in development, regeneration, and disease. Genes Dev. 2006; 20(13):1692-708.

2. Mauro A. Satellite cell of skeletal muscle fibers. J Biophys Biochem Cytol. 1961; 9: 493-5.

3. McLoon LK, Wirtschafter JD. Continuous myonuclear addition to single extraocular myofibers in uninjured adult rabbits. Muscle Nerve. 2002; 25(3);348-58. 
4. McLoon LK, Wirtschafter JD. Activated satellite cells in extraocular muscles of normal adult monkeys and humans. Invest Ophthalmol Vis Sci. 2003; 44(5): 1927-32.

5. McLoon LK, Wirtschafter JD. N-CAM is expressed in mature extraocular muscles in a pattern conserved among three species. Invest Ophthalmol Vis Sci. 1996; 37(2):318-27.

6. McLoon LK, Wirtschafter JD. Activated satellite cells are present in uninjured extraocular muscles of mature mice. Trans Am Ophthalmol Soc. 2002;100:119-23; discussion 123-4.

7. Christiansen SP, Sandnas A, Prill R, Youle R J, McLoon LK. Acute effects of skeletal muscle-specific immunotoxin ricinmAb 35 on extraocular muscles of rabbits. Invest Ophthalmol Vis Sci. 2000; 41(11): 3402-9.

8. Demer JL. Duane's Clinical Ophthalmology. Philadelphia: Lippincott Williams \& Wilkins; 2000.

9. Scott AB, Rosenbaum A, Collins CC. Pharmacologic weakening of extraocular muscles. Invest Ophthalmol Vis Sci. 1973;12(12): 924-7.

10. Scott AB. Botulinum toxin injection into extraocular muscles as an alternative to strabismus surgery. Ophthalmology. 1980;87(10):1044-9.
11. Ribeiro GB. Estudo da crotoxina na indução de paralisia da musculatura extrínseca ocular em modelo animal [tese]. Belo Horizonte: Faculdade de Medicina da UFMG; 2001.

12. Christiansen SP, Becker BA, Iaizzo PA, McLoon LK. Extraocular muscle force generation after ricin-mAb 35 injection: implications for strabismus treatment. J AAPOS. 2003; 7(1):1-6.

13. Ugalde I, Christiansen SP, McLoon LK. Botulinum toxin treatment of extraocular muscles in rabbits results in increased myofiber remodeling. Invest Ophthalmol Vis Sci 2005; 46(11):4114-20.

14. Porter JD, Strebeck S, Capra NF. Botulinum-induced changes in monkey eyelid muscle. Comparison with changes seen in extraocular muscle. Arch Ophthalmol. 1991; 109(3):396-404.

\section{Endereço para correspondência: Avenida Otávio Dias Moreira, 10 - Bom Clima CEP: 36046-050 - Juiz de Fora (MG), Brasil. E-mail: martahalfeld@acessa.com}

